\title{
Review
}

\section{Reproductive Biotechnology Options for Improving Livestock Production: A Review}

\author{
Atsbha Hadgu, DVM'; Haben Fesseha, MVSc, DVM²* \\ 'College of Veterinary Medicine, Addis Ababa University, P. O. Box 34, Bishoftu, Ethiopia \\ ${ }^{2}$ Department of Veterinary Surgery and Diagnostic Imaging, School of Veterinary Medicine, Wolaita Sodo University, P. O. Box I38, Wolaita Sodo, Ethiopia

\section{"Corresponding author} \\ Haben Fesseha, MVSc, DVM \\ Assistant Professor, Department of Veterinary Surgery and Diagnostic Imaging, School of Veterinary Medicine, Wolaita Sodo University, P. O. Box I38, Wolaita Sodo, \\ Ethiopia; E-mail: tseyon.h@gmail.com
}

\section{Article information}

Received: November 2I ${ }^{\text {st }}$ 2019; Revised: January 29 ${ }^{\text {th }}$, 2020; Accepted: February II ${ }^{\text {th }}, 2020$; Published: February $25^{\text {th }}, 2020$

\section{Cite this article}

Hadgu A, Fesseha H. Reproductive biotechnology options for improving livestock production:A review. Adv Food Technol Nutr Sci Open J. 2020; 6(I): I3-20. doi: I0.17|40/AFTNSOJ-6-164

\section{ABSTRACT}

Reproductive biotechnology is one of the options which have a role in the improvement of livestock. It is a technology that improves livestock production by improving the reproductive insufficiency of the animal through different techniques. These are artificial insemination (AI), cloning, estrus synchronization, embryo transfer (ET), transgenesis and in vitro fertilization. These techniques are very important techniques to advance livestock production and to meet the people's demands now-a-day. These reproductive biotechnologies have a dramatic effect on the world's economy through the improvement of livestock genetics, preventing disease, facilitate transportation, keeping endangered animals and reducing economic loss. Artificial insemination in animals was originally developed to control the spread of disease, avoiding the transport of animals with potential pathogens to other animal units for mating and avoiding physical contact between individuals. The use of semen extenders containing antibiotics also helped to prevent the transmission of bacterial diseases. AI is broadly used in developing countries including Ethiopia. Even if reproductive biotechnologies are effective to change livestock production status of the countries, they are not applied routinely due to the presence of different challenges. Therefore, this review highlighted the major reproductive biotechnology options and their roles in the improvement of livestock production.

Keywords

Artificial insemination; Estrus synchronization; Embryo transfer; Livestock; Reproductive biotechnology.

\section{INTRODUCTION}

$\mathrm{K}$ eeping livestock is an important risk reduction strategy for vulnerable communities, and livestock are important providers of nutrients and traction for growing crops in smallholder systems. ${ }^{1}$ In developed countries, livestock accounts for more than half of agricultural production, while in developing countries the share is about one-third. ${ }^{1}$ Livestock products contribute $17 \%$ to kilocalorie consumption and $33 \%$ to protein consumption worldwide, but there are large differences between developed and developing countries. ${ }^{2}$

The public consumption of animal products increases from time-to-time, for example, meat and milk are projected to grow at $2.9 \%$ and $2.7 \%$ per annum respectively, between the late
1990 to 2020. This 'livestock revolution' is also expected to result in increase in demand for pork $(60 \%)$, poultry meat $(80 \%)$ and red meat $(50 \%)$ by 2020 , with developing countries accounting for two-thirds of global meat consumption and more than half of global milk consumption. The trends in consumer demand for livestock products are driven primarily by growth in the human population, increases in income and urbanization and associated changes in consumption patterns. ${ }^{3}$

Reproduction is the backbone of animal production and productivity is the key to development. Reproductive inefficiency is one of the most important causes of economic losses in animal industries and it is realized throughout the world. Despite the remarkable advancement that has been made in the field of reproductive physiology in recent years, infertility due to low conception 
rate and high embryonic mortality rate remains a major problem. ${ }^{4}$

To meet future needs and to be able to sustain agricultural production, agricultural research and its applications need to use all emerging technologies one of which is modern reproductive biotechnologies. ${ }^{5}$ Thus, various assisted-reproductive techniques have been developed and refined to obtain a large number of offspring from genetically superior animals or obtain offspring from infertile (or subfertile) animals in addition to disease control. ${ }^{6,7}$

Reproductive biotechnologies intend to be used routinely to shorten generational intervals and to propagate genetic material among breeding animal populations. To achieve this goal, reproductive technologies have been developed in generations over the years, namely artificial insemination (AI), embryo transfer (ET), manipulation of fertilization in vitro (IVF), cloning and transgenesis. ${ }^{8}$ These, together with sperm separation techniques, including that of selection of spermatozoa for chromosomal sex (commonly named sex-sorting) all face today a strong wave of increasing commercialization. ${ }^{9}$ Hence, this review paper highlighted the reproductive biotechnology options and their roles in the improvement of livestock production.

\section{ROLES OF REPRODUCTIVE BIOTECHNOLOGY IN ANIMAL} PRODUCTION

Biotechnology is defined as a technique that uses living organisms to make or modify and improve products. The emergence and development of reproductive technologies have been driven by the economic gain offered by the potential increase in the number of offspring from genetically superior animals or simply to safeguard the genetic pool of infertile or sub-fertile animals. In other words, reproductive technologies were developed to offer possibilities for wider use of superior germplasm..$^{10,11}$

In recent times, there has been increasing challenges for increasing productivity and disease with altering climate. Advent and use of modern reproductive technologies have opened many avenues to study, treat and manipulate the reproductive phenomenon both in vitro and in vivo to improve reproductive performance in various domestic species of livestock. ${ }^{12}$

In cattle, estrus synchronization and AI can be used to maximize the reproductive potential of cows by incorporating superior genetics into their operations. The use of estrus synchronization timed AI protocols is beneficial to many farmers since it reduces the time and labor required for estrus detection. It also minimizes the frequency of animal handling. ${ }^{13}$

Assessing the fertilization capacity of sperms, sexing sperms, synchronization and fixed-time insemination, superovulation, ET and in vitro embryo production are additional techniques that can improve reproductive efficiency and pregnancy rates. Reproductive technologies can also be used to control reproductive diseases if procedures and protocols are accurately followed. The main objectives of using reproductive biotechnologies in livestock are to increase production, reproductive ef- ficiency and rates of genetic improvement. ${ }^{1,14}$

\section{THE FIRST THREE GENERATION OF REPRODUCTIVE BIOTECHNOLOGIES |}

Estrous synchronization and AI are reproductive management tools that have been available to beef producers for over 50 -years. Embryo transfer is generated in 1975 next to artificial insemination and estrous synchronization. ${ }^{15,16}$

\section{Artificial Insemination}

Artificial insemination (AI) has been defined as a process by which sperm is collected from the male, processed, stored, and artificially introduced into the female reproductive tract for the purpose of conception by using means other than sexual intercourse or natural insemination. ${ }^{17}$

Artificial insemination (AI) is used as a tool to enhance production efficiency in cattle and the successful use of AI as a means of animal breeding relies upon three major premises: firstly, that spermatozoa can survive outside the body; secondly, that they can be reintroduced into the female genital tract in a way that results in an acceptable conception rate; and thirdly, that the fertile period of the female can be identified. ${ }^{18,19}$

The timing of insemination is important as it can affect pregnancy rate which is correlated with estrus, ovulation, and rates of fertilization. The potential to pass high genetic merits of a selected male to thousands of females makes this a far more efficient technology for producing large numbers compared to female based technologies, such as embryo transfer, which can only produce a few progenies from a selected female. ${ }^{20,21}$

Techniques and application of artificial insemination: Semen is usually collected from bulls by the use of an artificial vagina or by electroejaculation. Semen collected by electroejaculation is often more dilute and may appear to be less motile than that collected by artificial vagina, although total sperm per ejaculate and sperm viability should be essentially similar assuming the electroejaculation collection has been successful and complete. Initial assessments require live sperm motility and should be done as quickly as possible after collection. ${ }^{22}$

Vaginal insemination the simplest method that could result in the lowest conception rate. The best method is inseminated via the insertion of "straws" in the vagina and through the cervix of animals in estrus and the cervix is therefore open and receptive. During insemination, one hand up the rectum and manipulating the cervix to help insertion of the insemination gun. Artificial insemination should be timed as close as possible to ovulation, preferably within 12 to 24 -hours before ovulation. ${ }^{23,24}$

Artificial insemination offers several potential advantages over natural service, of these, the reason most commonly advocated is as a means of genetic improvement and others include cost-effectiveness, disease control, safety breeding, flexibility and 
fertility management. ${ }^{25}$ Genetic progress in cattle can be increased up to $50 \%$ through the application of $\mathrm{AI}$, the first-generation biotechnology, using either extended semen that has been preserved in liquid form (fresh, or cooled to $5^{\circ} \mathrm{C}$ ) or deep-frozen. ${ }^{26}$

Both artificial insemination and embryo transfer improve breeding that increases milk yield which is not accompanied by improved health and proper nutrition can be realized at the expense of reduced fertility in dairy cows. Periods of stress due to inadequate nutrition or high milk yield reduce the intensity of estrous signs by affecting the endocrinology of behavior and ovarian function and compromise the outcome of AI or ET. Besides, venereal diseases have a great impact on AI regarding genetic improvement. ${ }^{27,28}$

\section{Estrus Synchronization}

Estrus detection is crucial and important for estrus synchronization and needs a good husbandry practice of cow. Thus, estrus synchronization is an alternative strategy to bypass the critical problem of estrus detection. Estrus synchronization is the process of bringing female animals to the heat state of those having preovulatory follicular activity using hormonal interventions that increases the probability of estrous detection and helps for timely insemination to increase conception rate..$^{29,30}$

Synchronization of estrus in cows is feasible by either curtailing or extending the length of estrus cycle, which can be maintained based on two principles; first one is using in-situ luteolytic agent (prostaglandin) that induces luteolysis of corpus luteum (CL) and exogenous administration of such agents mimics premature luteolysis and hence results in shortening of diestrus phase of estrus cycle; whereas, the second principles is lengthening of diestrus phase through maintenance of CL in terms of progesterone production which determines the length of diestrus phase (Figure 1). Hence, with the administration of progesterone hormone, the diestrus phase can be extended..$^{31}$

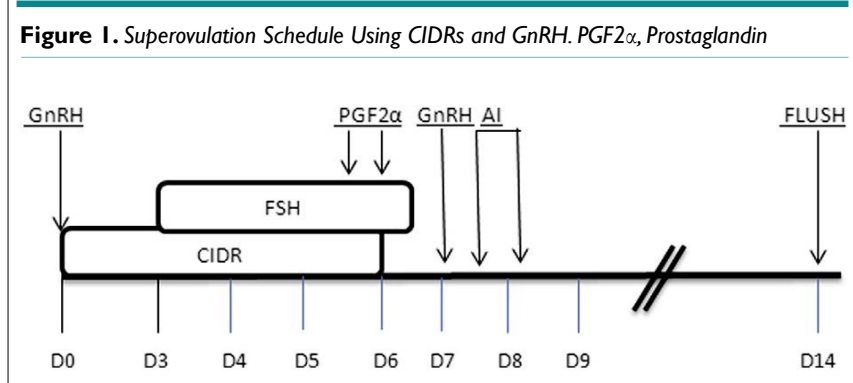

Adapted from Phillips $P E^{39}$

Role of Estrus synchronization: The synchronization program is one of the strategies for improving pregnancy rates in the modern beef and dairy industry that improves reproductive performance. This method provides breed with a high percentage of the females in a given group of heifers or cows in a short period of time, using either artificial insemination or natural ser- vice using bulls. ${ }^{32}$ Through effective application, it is possible to accomplish a greater number of calves with improved quality are obtained. Besides, effective synchronization facilitates estrus detection which is important for the application of artificial insemination. ${ }^{13,33}$

\section{Embryo Transfer}

Embryo transfer is a process by which an embryo is collected from a donor female and then transferred into a recipient female where the embryo completes its development. It is the most commonly used biotechnology after artificial insemination and estrus synchronization. Embryo transfer is profitable for producers of pure-bred animals and genetically superior female that produces more offspring than she could by natural reproduction. It is also used in several species of domestic animals including cows, horses, goats, and sheep. ${ }^{34,35}$

Embryo transfer is very expensive and many of the basic procedures were established some years ago. Consequently, little academic research currently is being conducted that is likely to immediately benefit the commercial industry. Because success rates in well-managed cattle herds are generally quite high, most recent improvements involve rather small, albeit important, increments. ${ }^{36}$ During embryo transfer, the animal should pass through. Some procedures starting from (i) Selection and preparation of donors, (ii) Collection of embryos, (iii) Handling, evaluation, and storage of embryo, (iv) Selection and preparation of recipients and (v) Practical embryo transfer. ${ }^{37,38}$

\section{Selection and Management of Donor and Recipient Cow}

The selection of superior genetic or phenotypic animals has been the basis of the donor selection since ET's in-ception. Genetic superiority animals that contribute to the genetic objectives of the program and the likelihood of producing large numbers of usable embryos are the two broad criteria for selecting donor cows for most embryo transfer programs. ${ }^{39,40}$ In fact, selecting the male is usually more important than selecting the donor female because males will normally be bred to many females and can be selected more accurately than females. Like-wise, it is necessary to select fertile bulls and fertile semen which makes it especially important to use high-quality semen. Donors are located either on the farm under production conditions or at an embryo transfer cen-ter, frequently under intensive management. Keeping donors on the farm is usually the less expensive alternative..$^{7,14}$

\section{Selection and Management of Recipient}

One of the most important yet underappreciated aspects of a successful ET program is the recipient. Cows that are reproductively sound, that exhibit calving ease, and that have good milking and mothering ability are recipient prospects. They must be on a proper plane of nutrition. These cows also must be on a sound herd health program. Proper recipient herd management is critical to ET success and this requires a fundamental understanding of the recipient selection, nutrition, estrus synchronization, dis- 
ease management, and marketing. ${ }^{7,41}$

\section{Synchronization of Recipient}

To maximize embryo survival in the recipient female following transfer, conditions in the recipient reproductive tract should closely resemble those in the donor. This requires synchronization of the estrous cycles between the donor and the recipients, optimally within one day of each other. Synchronization of the recipients can be done in a similar manner and at the same working time as the donor cows. ${ }^{37,39}$ Recipients synchronized with prostaglandin F2 $\alpha$ (PGF2 $\alpha$ ) must be treated 12 to 24-hours before donor cows because PGF $2 \alpha$-induced estrus will occur in recipients in 60 to 72 -hours ${ }^{14}$ and in superovulated donors in 36 to 48-hours. Synchronizing products are more effective on recipient females that are already cycling (Table 1). ${ }^{41}$

\begin{tabular}{|c|c|c|}
\hline $\begin{array}{l}\text { Days in } \\
\text { Sequence }\end{array}$ & $\begin{array}{l}\text { Time of the } \\
\text { Day }\end{array}$ & Activity \\
\hline 1 & $8.00-10.00$ AM & Inject $20 \mathrm{ml}$ multivitamine \\
\hline 7 & $8.00-10.00$ AM & Insert CIDR device $+2 \mathrm{ml}$ ciderol \\
\hline 12 & $8.00-10.00$ AM & Inject Estrumate \\
\hline 14 & $8.00-10.00$ AM & Inject Estrumate \\
\hline 15 & $8.00-10.00 \mathrm{AM}$ & Remove CIDR device \\
\hline 16 & $8.00-10.00$ AM & Observe heat \\
\hline 24 & 8.00 AM-5.00 PM & Transfer \\
\hline \multicolumn{3}{|c|}{$\begin{array}{l}\text { CIDR }=(\text { Controlled Internal Drug Release device }) \\
\text { Source: Data from the Ongubo et al }{ }^{42}\end{array}$} \\
\hline
\end{tabular}

\section{Superovulation of Donor}

Superovulation refers to the release of many oocytes (eggs) during a single estrus period. ${ }^{6}$ Once the donor cow is selected, the first step is to superovulate or produce multiple ova (eggs) for simultaneous fertilization and subsequent collection. Initially, the donor female is treated with a gonadotropin hormone called follicle-stimulating hormone (FSH). This hormone is administered twice daily for four days in the range of eight to fourteen days while a functional CL is on the ovary. A PGF2 $\alpha$ injection given on the fourth day of the treatment schedule will cause CL regression and estrus to occur approximately 48-hours later. As a result of treatment, multiple follicles should be developed on the ovaries of the donor. Multiple numbers of eggs will be released at estrus, one from each follicle. ${ }^{43}$

\section{General Procedure}

The actual embryo transfer process is similar to the method used for artificial insemination, except that the transfer gun is passed well up the uterine horn ipsilateral to the CL. The donor may be inseminated naturally or artificially and embryos will be collected non-surgically six to eight-days after breeding. Following collection, embryos must be identified, evaluated and maintained in a suitable medium prior to transfer. At this point, they may also be subjected to manipulations, such as splitting and sexing, and may be cooled or frozen for longer periods of storage..$^{44,45}$

\section{OTHER REPRODUCTIVE BIOTECHNOLOGIES}

\section{Cloning}

Cloning refers to producing genetically identical individual to donor cells and copying gene, that involves the creation of an animal or individual that derives its genes from a single other individual; it is also referred as "Asexual reproduction". Embryo splitting and nuclear transfer are methods of cloning, where an embryo is splitting in the maturation soon after fertilization of the egg by the sperm before embryo transfer. It is optimally performed at the 6-to 8-cell stage, where it can be used as an expansion of IVF to increase the number of available embryos. ${ }^{46}$

Cloning can be used along with other forms of assisted reproduction to help preserve indigenous breed of livestock, that have production trial and adaptability to local environments that should not be lost from the global gene pool. It also enables the rapid dissemination of superior genotypes from nucleus breeding flock and herds, directly to commercial farmers. Cloning technology has the potential to stimulate the development of the animal biotechnology industry in many countries of the world, as well as provide conservationists with an additional tool to assist with conserving critically endangered wildlife species. ${ }^{47-49}$

\section{Sex Determination}

Sex determination of embryo: The sexual differentiation of the embryo is determined by the presence or absence of elements normally located on the Y-chromosome. Some of the techniques employed commercially for the embryo sexing are chromosomal analysis of demi-embryos, immunological detection of embryonic H- Y antigen, use of Y-specific probes, Fluorescence in situ hybridization, rapid sexing method for preimplantation embryos of bovine using loop-mediated isothermal amplification (LAMP) reaction and ultrasonic examination of fetal structures. ${ }^{50}$

Predetermination of the sex of offspring provides a greater number of males or females and helps in the selection of individuals with top genetic makeup for improvement in nextgeneration. ${ }^{51}$ Known sex of embryos produced for use in ET programs can more effectively help to manage producer resources because more heifer calves per ET can be produced. Semen sexing can be used in IVF and AI programs. ${ }^{50,52}$

Sex determination of semen: Semen sexing is the process of separating spermatozoa into two subpopulations containing $\mathrm{X}$ chromosome and Y-chromosome bearing spermatozoa. Sexing spermatozoa for directed production of offspring of a desirable sex by use of modified flow cytometric cell sorting of fluorescent dye loaded living spermatozoa. Cattle have about 3.8\% differences in deoxyribonucleic acid (DNA) contents between their X and Y-chromosome bearing spermatozoa, a difference large enough to allow successful sorting. This technique involves the separation of $\mathrm{X}$ - and $\mathrm{Y}$ - bearing spermatozoa in small quantities based on 
the DNA content of the spermatozoa. ${ }^{9}$

Sperm sexing technology (SST) will enable the producers of livestock to predetermine the sex of offspring prior to conception, thereby maximizing productivity, profitability, and genetic potential. In virtually every sector of commercial animal breeding, there is a clear preference for one sex over the other. The sexed sperm can be utilized for AI or for in vivo and in vitro embryo production. ${ }^{53}$

\section{Transgenesis}

A transgenic animal is one that carries a foreign gene that has been deliberately inserted into its genome. It is the one that has been genetically altered to have specific characteristics it otherwise would not have. Transgenic animals are genetically modified to contain a gene from a different species following gene transplantation or resulting from the molecular manipulations of endogenous genomic DNA. The new gene is inherited by offspring in the same way as the organism's own genes. ${ }^{54}$ There are different methods of transgenesis such as DNA microinjection, ${ }^{55} \mathrm{DNA}$ transfer into gametes, ${ }^{56}$ DNA Electroporation. ${ }^{57}$

Transgenic farm animals can be used both in breeding and biomedicine. In breeding, transgenic individuals produced are equipped with disease resistance and improved quantitative and qualitative traits. Transgenic cows producing milk of increased $\hat{a}$ caseine and $\hat{e}$-caseine content. An important achievement was the production of transgenic cows resistant to mastitis. Researches are going on for the production of environment-friendly transgenic individuals or using such animals in basic studies as a model to understand various physiological processes in farm animals and humans. ${ }^{58,59}$

\section{In vitro Fertilization (IVF)}

The fertilization of the sperm and the egg is conducted in vitro at specific environmental and biochemical conditions. With IVF, a technician removes unfertilized eggs (oocytes) from the donor cow's ovaries, usually recovering 6-8 useable oocytes. The oocytes mature in an incubator and are fertilized with sperm. The resulting zygotes incubate and develop in the laboratory before being placed into the recipient cow. ${ }^{34}$

In vitro fertilization of the oocytes is usually carried out following 24-hour maturation in the IVM medium. Surrounding cumulus cells are removed by gentle pipetting and washing in fertilization medium and groups of 40-50 oocytes are placed in 4-well dishes in $500 \mu \mathrm{l}$ of synthetic oviductal fluid covered by 200 $\mu \mathrm{l}$ of mineral oil. ${ }^{60}$

Motile sperm are obtained by centrifugation of frozenthawed semen in the percoll gradient $(45 \% / 90 \%)$ at 500 grams for 10-minutes at room temperature. Percoll gradient separation of spermatozoa seems to be an effective means of yielding motile sperm from frozen-thawed semen. Although 17-hour coincubation is practiced in IVF, it has been shown that even 4-hour coincubation was enough to obtain acceptable cleavage and blasto- cyst rates in sheep. Further application of IVF in obtaining sex pre-determined offspring will be an advantage for the livestock industry. ${ }^{61,62}$

\section{CONCLUSION AND RECOMMENDATION}

Reproductive Biotechnology is modern and recent technological techniques that use biological systems and organisms to develop, modify and increase quality products. The application of biotechnology offers numerous advantages to livestock production through enhancement and control of reproductive processes in animals. It is within this scope that the reproductive biotechnology techniques have contributed tremendously to the satisfaction of the increasing demands of the modern dairy and beef industries.

Many producers are now familiar with more advanced methods of reproductive biotechnologies to enhance reproductive efficiency, which further adds potential economic efficiency to cattle industries. These are artificial insemination, cloning, estrus synchronization, embryo transfer, transgenesis and in vitro fertilization. Artificial insemination is the broadly used technologies in the genetic improvement of animals and preventing animal diseases in developed and developing countries.

The other biotechnologies also have different roles through preserve extinct animal gametes, reducing costs, controlling the natural behavior of animals, producing of very important breed in a short time and controlling reproductive diseases if procedures and protocols are accurately followed. These technologies have a great role in improving the dairy and beef industry. Besides, developing countries should be familiarized with the technologies which help them to advance their dairy industries by improving both the quality and quantity of products with good practices in animal husbandry and management (Figure 2).

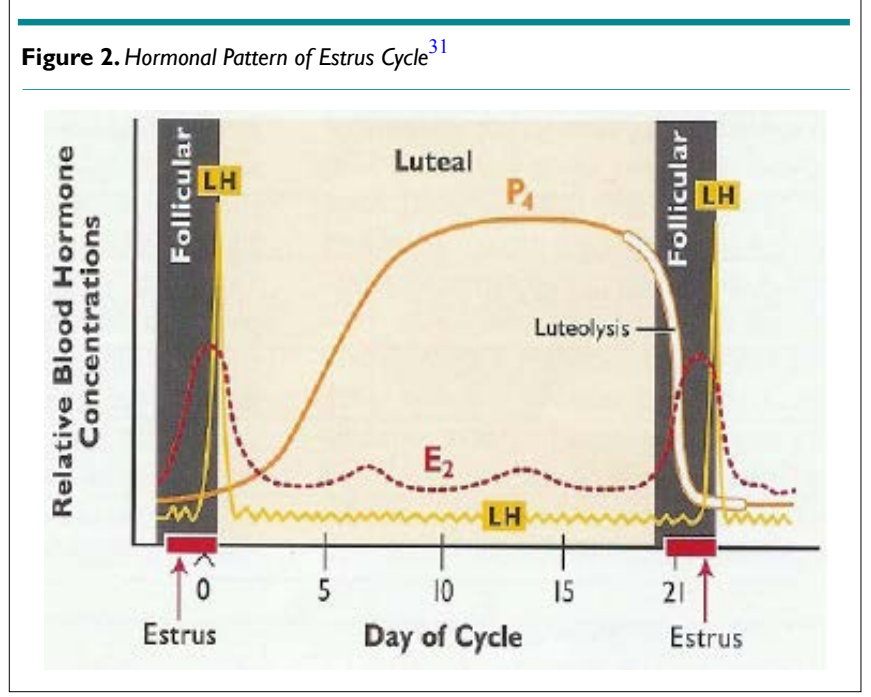

\section{ACKNOWLEDGMENT}

My special and grateful gratitude goes for my familie for their financial, material and moral support and for Dr. Haben Fesseha 
reproductive biotechnologies. Veterinary World. 2016; 9(4): 388395. doi: 10.14202/vetworld.2016.388-395 ration. The last but not least gratitude goes for my entire friends for their advice, motivation, and encouragement in the preparation of this paper.

\section{CONFLICTS OF INTEREST |}

The authors declare that they have no conflicts of interest.

\section{REFERENCES}

1. Madan ML. Animal biotechnology: applications and economic implications in developing countries. Rev Sci Tech. 2005; 24(1): 127-139.

2. Rosegrant MW, Fernandez M, Sinha A, et al. Looking into the future for agriculture and AKST. Web site. https://cgspace.cgiar. org/handle/10568/37336?show=full. Accessed November 20, 2019.

3. Gale HF, Ping T, Xianhong B, Huijun X. Commercialization of food consumption in rural China. USDA-ERS Economic Research Report 8. 2005. doi: 10.22004/ag.econ.7256

4. Verma OP, Kumar R, Kumar A, Chand S. Assisted reproductive techniques in farm animal-from artificial insemination to nanobiotechnology. Veterinary World. 2012; 5(5): 301-310. doi: 10.5455/vetworld.2012.301-310

5. Holtz W. Recent developments in assisted reproduction in goats. Small Ruminant Research. 2005; 60(1-2): 95-110. doi: 10.1016/j.smallrumres.2005.06.032

6. Mapletoft R. History and perspectives on bovine embryo transfer. Anim Reprodu. 2013; 10(3): 168-173.

7. Widayati DT. Embryo transfer as an assisted reproductive technology in farm animals. World Acad Sci Eng Technol. 2012; 6: 10-21. doi: $10.5281 /$ zenodo.1061796

8. Morrell J, Rodriguez-Martinez H. Practical applications of sperm selection techniques as a tool for improving reproductive efficiency. Vet Med Int. 2010; 2011: 1-9. doi: 10.4061/2011/894767

9. Garner D, Seidel JG. History of commercializing sexed semen for cattle. Theriogenology. 2008; 69(7): 886-895. doi: 10.1016/j.theriogenology.2008.01.006

10. Moore K, Thatcher W. Major advances associated with reproduction in dairy cattle. I Dairy Sci. 2006; 89(4): 1254-1266. doi: $10.3168 / j d s . S 0022-0302(06) 72194-4$

11. Olatunji O. Biotechnology and industries in Nigeria. Paper presented at: Proceeding $20^{\text {th }}$ Annual National Conference of Biotechnology Society of Nigeria; 2007; Abakaliki, Nigeria.

12. Choudhary K, Kavya K, Jerome A, Sharma R. Advances in
13. Leitman N, Busch D, Mallory D, et al. Comparison of longterm CIDR-based protocols to synchronize estrus in beef heifers. Anim Reprod Sci. 2009; 114(4): 345-355. doi: 10.1016/j.anireprosci.2008.10.014

14. Getachew BF. Use of biotechnology in livestock production and productivites: A review. International Journal of Research Granthaalayah. 2016; 4(6): 100-109. doi: 10.5281/zenodo.56631

15. Lamb C. What are the long-term impacts of estrus synchronization and artificial insemination? Web site. http://nwdistrict. ifas.ufl.edu/phag/2015/10/09/what-are-the-long-term-impacts-of-estrus-synchronization-and-artificial-insemination/. Accessed November 20, 2019.

16. Thibier M. The zootechnical applications of biotechnology in animal reproduction: current methods and perspectives. Reprod Nutr Dev. 2005; 45(3): 235-242. doi: 10.1051/rnd:2005016

17. Long JA. Reproductive biotechnology and gene mapping: Tools for conserving rare breeds of livestock. Reprod Domest Anim. 2008; 43: 83-88. doi: 10.1111/j.1439-0531.2008.01146.x

18. Holm D, Thompson P, Irons P. The economic effects of an estrus synchronization protocol using prostaglandin in beef heifers. Theriogenology. 2008; 70(9): 1507-1515. doi: 10.1016/j.theriogenology.2008.06.098

19. Manafi M. Artificial insemination in farm animals. In: Theriogenology. London, UK: IntechOpen Publisher; 2011.

20. Johnson LA, Rath D, Vazquez JM, Maxwell WM, Dobrinsky JR. Preselection of sex of offspring in swine for production: Current status of the process and its application. Theriogenology. 2005; 63(2): 615-624. doi: 10.1016/j.theriogenology.2004.09.035

21. Maquivar M, Verduzco A, Galina C, et al. Relationship among follicular growth, oestrus, time of ovulation, endogenous estradiol $17 \beta$ and luteinizing hormone in Bos indicus cows after a synchronization program. Reprod Domest Anim. 2007; 42(6): 571-576. doi: 10.1111/j.1439-0531.2006.00821.x

22. Peter JC. Applied reproductive strategies in beef cattle. Paper presented at: Proceedings, semen evaluation; 2004; North Platte, Nebraska.

23. Anel L, Kaabi M, Abroug B, et al. Factors influencing the success of vaginal and laparoscopic artificial insemination in churra ewes: A field assay. Theriogenology. 2005; 63(4): 1235-1247. doi: 10.1016/j.theriogenology.2004.07.001

24. De Jong E, Vanderhaeghe C, Beek J, et al. Ultrasonography of the ovaries in the sow: a helpful tool to determine the time of insemination. Vlaams Diergeneeskundig Tijdschrift. 2009; 78: 276-281. 
25. Ball PJ, Peters AR. Reproduction in Cattle. $3^{\text {rd }}$ ed. Hoboken, New Jersey: United Kingdom Blackwell Publishing Ltd; 2004.

26. Vishwanath R. Artificial insemination: The state of the art. Theriogenology. 2003; 59(2): 571-584. doi: 10.1016/S0093691X $(02) 01241-4$

27. Foote R. Within-herd use of boar semen at $5{ }^{\circ} \mathrm{C}$, with a note on electronic monitoring of oestrus. Reprod Domest Anim. 2002; 37(1): 61-63. doi: 10.1046/j.1439-0531.2002.00328.x

28. Rodriguez-Martinez H, Hultgren J, Båge R, et al. Reproductive performance in high-producing dairy cows: Can we sustain it under current practice. IVIS Reviews in Veterinary Medicine. 2008; 1(108): 1-23.

29. Lucy M, McDougall S, Nation D. The use of hormonal treatments to improve the reproductive performance of lactating dairy cows in feedlot or pasture-based management systems. Anim Reprod Sci. 2004; 82: 495-512. doi: 10.1016/j.anireprosci.2004.05.004

30. Paul AK, Yoisungnern T, Bunaparte N. Hormonal treatment and estrus synchronization in cows: A mini-review. $J$ Adv Vet Anim Res. 2015; 2(1): 10-17. doi: 10.5455/javar.2015.b45

31. Worku A. Assessment of breeding practices and evaluation of Mass Oestrus Syncronization and Mass Insemination Techniques in Dairy Cattle in West Shoa Zone, [master's thesis]. Dire Dawa, Ethiopia: Haramaya University; 2015.

32. Noseir WM. Ovarian follicular activity and hormonal profile during estrous cycle in cows: The development of 2 versus 3 waves. Reprod Biol Endocrinol. 2003; 1(1): 50. doi: 10.1186/14777827-1-50

33. Blezinger SB. Estrous synchronization a valuable tool in management of cows and heifers. Cattle Today, INC. 2000.

34. Cowan T, Becker GS. Biotechnology in animal agriculture: Status and current issues. Congressional Research Service. Web site. https://nationalaglawcenter.org/wp-content/uploads/assets/crs/RL33334.pdf. 2010. Accessed November 2, 2019.

35. Stroud B, International Embryo Transfer Society's (IETS). Statistics and data retrieval committee report. Embryo Transfer Newsletter. 2012; 30: 15-26.

36. Betteridge KJ. A history of farm animal embryo transfer and some associated techniques. Animal Reprod Sci. 2003; 79(3-4): 203244. doi: 10.1016/s0378-4320(03)00166-0

37. Larson J, Lamb G, Funnell B, Bird S, Martins A, Rodgers J. Embryo production in superovulated Angus cows inseminated four times with sexed-sorted or conventional, frozen-thawed semen. Theriogenology. 2010; 73(5): 698-703. doi: 10.1016/j.theriogenology.2009.11.009
38. Trasorras V, Chaves MG, Neild D, Gambarotta M, Aba M, Agüero A. Embryo transfer technique: Factors affecting the viability of the corpus luteum in llamas. Anim Reprod Sci. 2010; 121(3-4): 279-285. doi: 10.1016/j.anireprosci.2010.06.004

39. Phillips PE, Jahnke MM. Embryo transfer (techniques, donors, and recipients). Vet Clin North Am Food Anim Pract. 2016; 32(2): 365-385. doi: 10.1016/j.cvfa.2016.01.008

40. Thibier M. Data retrieval committee annual report. IETS Newslett. 2006; 24: 12-18.

41. Warriach H, McGill D, Bush R, Wynn P, Chohan K. A review of recent developments in buffalo reproduction-a review. Asian-Australas J Anim Sci. 2015; 28(3): 451-455. doi: 10.5713/ ajas.14.0259

42. Ongubo M, Rachuonyo H, Lusweti F, et al. Factors affecting conception rates in cattle following embryo transfer. Uganda Journal of Agricultural Sciences. 2015; 16(1): 19-27. doi: 10.4314/ujas. v16i1.2

43. Blizinger SB. Embryo transfers becoming more popular with procedures, cattle today. Web site. http://www.cattletoday.com/ archive/2007/May/CT987.shtml. Accessed on November 02, 2007.

44. Hasler J. Factors influencing the success of embryo transfer in cattle. Medecin Veterinaire Du Quebec. 2004; 34: 66-66.

45. Hasler JF. The current status and future of commercial embryo transfer in cattle. Anim Reprod Sci. 2003; 79(3-4): 245-264. doi: 10.1016/s0378-4320(03)00167-2

46. Reik W. Stability and flexibility of epigenetic gene regulation in mammalian development. Nature. 2007; 447(7143): 425-432. doi: $10.1038 /$ nature 05918

47. Morley K. Cloning technique. Web site. http://www.uq.edu. au. Office of public policy and Ethics Institute for molecular Bioscience: University of Queensland Australia; 2002; Brisbane, Australia. Accessed November 22, 2019.

48. Vajta G, Gjerris M. Science and technology of farm animal cloning: State of the art. Anim Reprod Sci. 2006; 92(3-4): 211-230. doi: 10.1016/j.anireprosci.2005.12.001

49. Wells D. Animal cloning: Problems and prospects. Rev Sci Tech. 2005; 24(1): 251-264.

50. Zoheir KM, Allam AA. A rapid method for sexing the bovine embryo. Animal Reprod Sci. 2010; 119 (1-2): 92-96. doi: 10.1016/j. anireprosci.2009.12.013

51. Plummer WE, Beckett D. Development of successful sex determination method of bovine embryos utilizing embryo biopsy and PCR. Anim Sci. 2006. 
52. Maxwell W, Johnson L. Chlortetracycline analysis of boar spermatozoa after incubation, flow cytometric sorting, cooling, or cryopreservation. Mol Reprod Dev. 1997; 46(3): 408418. doi: 10.1002/(SICI)1098-2795(199703)46:3<408::AIDMRD21>3.0.CO;2-T

53. Seidel JG. Overview of sexing sperm. Theriogenology. 2007; 68(3): 443-446. doi: 10.1016/j.theriogenology.2007.04.005

54. Rajoriya R, Rajoriya S, Kumar N. Transgenic animals: Prospects for improving livestock productivity. J Bio Innov. 2013; 2(5): 240-259.

55. Krimpenfort P, Rademakers A, Eyestone W, et al. Generation of transgenic dairy cattle using 'in vitro'embryo production. Biotechnology. 1991; 9(9): 844-847. doi: 10.1038/nbt0991-844

56. Baccetti B, Spadafora C. Sperm-mediated gene transfer: Advances in sperm cell research and applications. Mol Reprod Dev. 2000; 56: 329-330.

57. Transgenics T. Taconic W4/129S6 Embryonic Stem Cells. Web site. http://www.taconic.com/emerging/ESCells/ES_ WEB.htm. Accessed November 22, 2019.
58. Niemann H, Kues W, Carnwath J. Transgenic farm animals: Present and future. Rev Sci Tech. 2005; 24(1): 285-298.

59. Wells DJ. Genetically modified animals and pharmacological research. Handb Exp Pharmacol. 2010; (199): 213-226. doi: 10.1007/978-3-642-10324-7_9

60. Coppola G, Alexander B, Di Berardino D, St John E, Basrur PK, King WA. Use of cross-species in-situ hybridization (ZOOFISH) to assess chromosome abnormalities in day- 6 in-vivo-or in-vitro-produced sheep embryos. Chromosome Res. 2007; 15(3): 399-408. doi: 10.1007/s10577-007-1125-2

61. Cognie Y, Baril G, Poulin N, Mermillod P. Current status of embryo technologies in sheep and goat. Theriogenology. 2003; 59(1): 171-188. doi: 10.1016/s0093-691x(02)01270-0

62. O’Brien J, Hollinshead F, Evans G, Maxwell W. In vivo developmental capacity of in vitro-produced embryos derived from sex-sorted and re-cryopreserved frozen-thawed ram sperm. Reproduction, Fertility and Development. 2003; 16(2): 286-286. doi: 10.1071/RDv16n1Ab332 